
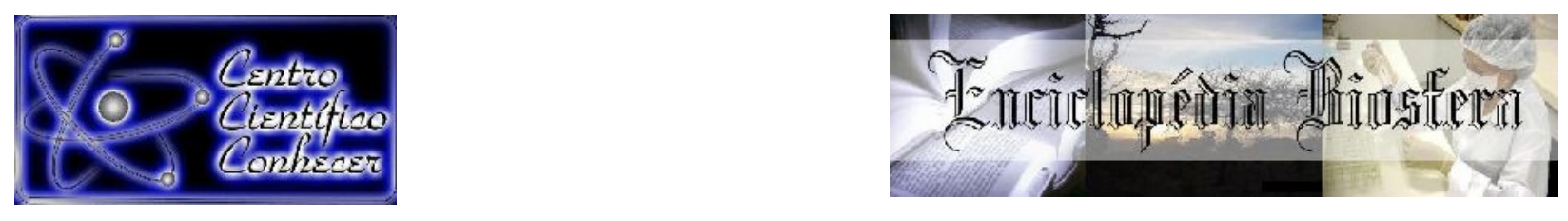

\title{
ASPECTOS DA PRODUÇÃO, COMERCIALIZACCÃO E DESENVOLVIMENTO DA CULTURA DA PITAYA NO ESTADO DO PARÁ
}

Paulo Silvano Magno Fróes Júnior ${ }^{1}$, Nicole Raquel Pinto Cardoso ${ }^{2}$, Fabrício Khoury Rebello ${ }^{3}$, Alfredo Kingo Oyama Homma ${ }^{4}$, Maria Lúcia Bahia Lopes ${ }^{5}$

${ }^{1}$ Engenheiro Agrônomo, mestrando do Programa de Pós-Graduação em Agronomia (PGAGRO) da Universidade Federal Rural da Amazônia (UFRA), Belém, Brasil.

E-mail: pjfroes@yahoo.com.br

2 Engenheira Agrônoma, mestranda do Programa de Pós-Graduação Agronomia

(PGAGRO) da Universidade Federal Rural da Amazônia (UFRA), Belém, Brasil.

${ }^{3}$ Prof. Dr. do Programa de Pós-Graduação em Agronomia (PGAGRO) da

Universidade Federal Rural da Amazônia (UFRA), Belém, Brasil.

${ }^{4}$ Dr. em Economia Rural. Pesquisador da Embrapa Amazônia Oriental, Belém, Brasil.

${ }^{5}$ Profa. Dra. do Programa de Pós-Graduação em Desenvolvimento e Meio Ambiente Urbano da Universidade da Amazônia (UNAMA), Belém, Brasil.

Recebido em: 06/04/2019 - Aprovado em: 10/06/2019 - Publicado em: 30/06/2019 DOI: 10.18677/EnciBio_2019A19

O presente artigo faz uma análise exploratória sobre a conjuntura de mercado da pitaya no Estado do Pará, investigando as oportunidades e desafios dessa fruteira na economia paraense. Para atingir o objetivo da pesquisa, realizou-se uma revisão de literatura sobre a cultura no cenário mundial, nacional e regional que dialogou com dados de produção do Instituto Brasileiro de Geografia e Estatística (IBGE) e informações de preço no varejo da Central de Abastecimento do Pará (CEASA-PA), referentes ao período de março de 2017 a janeiro de 2019, além de contar com observações de campo. Os preços foram deflacionados para o mês de fevereiro de 2019 pelo Índice Geral de Preços Disponibilidade Interna (IGP-DI). Observou-se que o Estado do Pará é o quarto maior produtor nacional de pitaya do País (com 10,47\% da produção nacional), tendo o município de Tomé-Açu como principal polo produtivo (92,70 toneladas, em 2017). Por se tratar de uma fruta exótica, ainda existe um grande desconhecimento do mercado consumidor, havendo a necessidade de pesquisas de melhoramento genético e melhoria de fatores físicoquímicos dos frutos, que tem efeito no sabor. Foi observado que as características gustativas do fruto têm grande influência na tomada de decisão de compra pelo novo consumidor, assim como o preço considerado caro que, atualmente, gira em torno de $R \$ 13,12 / \mathrm{kg}$ na CEASA-PA.

PALAVRAS-CHAVE: Amazônia, Fruticultura, Hylocereus, Mercado Agrícola. 


\title{
ASPECTS OF PRODUCTION, COMMERCIALIZATION AND DEVELOPMENT OF DRAGON FRUIT CROP AT STATE OF PARÁ
}

\begin{abstract}
The present article does an exploratory analysis about the market conjuncture of Dragon Fruit in the State of Pará. It investigates the opportunities and challenges of this fruit in the paraense economics. With the objective of achieve the goals of this survey, a literature review related to the crop in the world, national and regional scenarios is done. This dialogues with the production data from the Brazil and the state obtained at Instituto Brasileiro de Geografia e Estatística (IGBE) and piece of information about price from Central de Abastecimento do Pará (CEASA-PA) referents to the period between March of 2017 and January of 2019, beyond some field works. The prices were deflated to the month of February of 2019 by the Índice Geral de Preços Disponibilidade Interna (IGP-DI). In the results were observed that State of Pará is the fourth major national producer of Dragon Fruit crop (with about $10.47 \%$ of the national production), with the municipality of Tomé-Açu as the main producer pole (92.70 tons in 2017). Because of it be an exotic fruit, still exists a huge lack of knowledge about the consumer market. It demands researches of genetic enhancement and improvement of physical-chemical proprieties of the fruits, which has a direct effect in the flavor. Then, the gustative characteristics were observed as a big influence in the currently decision-making of buy from the new consumer, as well as the price that is considered expensive, with about $R \$ 13,12 / \mathrm{Kg}$ in the CEASAPA.
\end{abstract}

KEYWORDS: Amazon, Agricultural Market, Fruticulture, Hylocereus.

\section{INTRODUÇÃO}

O mercado de frutas exóticas, em razão da abertura dos consumidores a novos produtos, tem mostrado uma perspectiva de crescimento no cenário nacional. Na região amazônica, as frutas exóticas como: maçã, laranja, banana, uva, mamão hawai, melão, entre outras fruteiras, a despeito de algumas destas serem produzidos nas regiões Sul e Sudeste do Brasil, têm sido vendidas a preços inferiores aos das frutas nativas, ainda no domínio do extrativismo (HOMMA, 2017).

No Estado do Pará os preços das frutas exóticas como da pitaya, mangostão, rambutan, entre outras, ainda são superiores aos das frutas tradicionais, o que é uma limitação para o consumo desses produtos pelas classes de menor renda. Contudo, apesar dessa perspectiva, o consumo de frutas tem conseguido manter 0 crescimento nos últimos anos (SEBRAE, 2017).

Nesse contexto, o mercado de frutas exóticas não convencionais, a despeito do seu preço, tem registrado aumento de vendas (SEBRAE, 2017). A pitaya, por se tratar de uma fruta exótica de introdução recente, tem sido bem valorizada e tem alcançado alto valor de mercado, oportunizando alta densidade de renda por área cultivada (PITAYA DO BRASIL, 2019) e tem despertado o interesse dos fruticultores em seu plantio e cultivo (CORDEIRO et al., 2015).

A pitaya é uma planta que tem origem nas Américas Central e do Sul, mais precisamente no México (PERWEEN et al., 2018; MIZRAHI et al., 1997; ESQUIVEL; AYARA-QUESADA, 2012). Segundo Nunes et al. (2014) estudos etnobotânicos relatam que índios americanos, principalmente do México, há tempos atrás utilizavam esses frutos para alimentação humana e animal, bem como para fins fitoterápicos. Por serem considerados pobres, gerou-se um preconceito com estes 
frutos, fazendo com que as espécies do gênero fossem marginalizadas e assim, restringindo-as comercialmente às classes de menor poder aquisitivo.

A planta apresenta rusticidade (JUNQUEIRA et al., 2002) fazendo parte de espécies variadas de cactos epífitos (PITAYA DO BRASIL, 2019), pertencendo a Família Botânica Cactaceae e possuindo quatro gêneros principais documentados: Stenocereus, Cereus, Selenicereus e Hylocereus (MOREIRA et al.; 2017). Os cactos trepadores do gênero Hylocereus são nativos das regiões tropicais da América do Norte, Central e América do Sul (ESQUIVEL, 2004).

Segundo Moreira et al. (2017) as espécies da planta mais conhecidas são a: pitaya amarela, de casca amarela e polpa branca (Selenicereus megalanthus); e, pitaya vermelha, com a casca vermelha e a polpa branca ou vermelha (Hylocereus sp.). Rezende et al. (2017) afirmam que a pitaya vermelha de polpa branca (Hylocereus undatus) é a mais presente no Brasil. As flores das pitayas vermelha e amarela são parecidas, grandes e brancas, e após a sua polinização produzem os frutos em cerca de dois meses até seis meses para o caso da amarela. A pitaya amarela ainda é pouco produzida no Brasil, sendo importada da Colômbia. É, no entanto, considerada de melhor qualidade que a vermelha (TODAFRUTA, 2019).

A pitaya é um fruto do tipo baga, com tamanho médio, formato globuloso e subglobuloso. Sua coloração pode alcançar a tonalidade verde em sua fase imatura e amarela ou vermelha quando madura. A polpa apresenta cores que variam do vermelho púrpura brilhante ao branco, com inúmeras sementes escuras comestíveis que se encontram distribuídas por toda a polpa (NUNES et al., 2014; ESQUIVEL; AYARA-QUESADA, 2012).

Perween et al. (2018) afirmam que o fruto possui várias propriedades nutracêuticas que são benéficas a saúde. A pitaya é rica em flavonoides, possui um alto teor de vitamina $\mathrm{C}$ e Vitaminas do Complexo B (B1, B2 e B3), elevados teores de fibra, nitrogênio, potássio, cálcio, ferro, manganês e zinco (CORDEIRO et al., 2015), por esta razão começou a ser apreciada pelo consumidor brasileiro, sendo considerada como superfruta por ser rica em nutrientes (MELQUÍADES JÚNIOR, 2018).

De acordo com Nunes et al. (2014) a pitaya era utilizada por povos da América do Sul como remédio para algumas doenças, como infecções intestinais e deficiências alimentares. Os benefícios que o fruto pode proporcionar a saúde são inúmeros, como, por exemplo: o combate a problemas cardiovasculares, controle de açúcar no sangue em diabéticos e benefícios para flora intestinal (PITAYA DO BRASIL, 2019), ajuda no tratamento de corrimento vaginal, gripes, asmas e é rico em antioxidantes que evitam o envelhecimento precoce (PERWEEN et al., 2018).

A cultura da pitaya apresenta diversas finalidades além do consumo do produto in natura. O fruto pode, também, ser utilizado para produção de medicamentos, uso em cosméticos (PITAYA DO BRASIL, 2019), corantes naturais e devido ao sabor adocicado da fruta, vem sendo utilizada na fabricação de vinhos, sucos, chás, doces como sorvetes, pudins, bolos, geleias, culinária em geral, além de outras infinidades de usos (GREENME, 2017).

No Estado do Pará, apesar do cenário produtivo da pitaya ainda não ser expressivo quando comparado com outras fruteiras regionais, percebe-se uma sutil movimentação por parte de alguns produtores em cultivar o fruto e de pesquisadores em compreender o comportamento produtivo e comercial da planta na região.

Este estudo tem o objetivo de apresentar uma análise exploratória da conjuntura de mercado da pitaya no Estado do Pará, investigando sobre as oportunidades e desafios dessa fruteira, bem como estimular novas pesquisas na 
área agronômica e da socioeconômica, particularmente quanto ao potencial de mercado e viabilidade econômico-financeira de seu cultivo comercial.

\section{MATERIAL E MÉTODOS}

A pesquisa foi realizada com base em revisão de literatura no Portal de Periódicos da Capes e no Google Acadêmico sobre a conjuntura produtiva e de mercado da cultura da pitaya no mundo, no Brasil e no Estado do Pará. O estudo utiliza dados da produção agrícola do Censo Agropecuário 2017 do Instituto Brasileiro de Geografia e Estatística (IBGE, 2019), apresentado informações quantitativas sobre a produção de pitaya nos cenários brasileiro e paraense.

Além disso, levantou-se dados da Central de Abastecimento do Pará (CEASAPA, 2019), referente ao período de março de 2017 a janeiro de 2019, para analisar os preços do produto no mercado paraense. Os preços foram deflacionados para o mês de fevereiro de 2019, por meio do Índice Geral de Preços Disponibilidade Interna (IGP-DI) da Fundação Getúlio Vargas, coletados junto ao Instituto de Pesquisa Econômica Aplicada (IPEA, 2019). Utilizou-se a Equação 1 para cálculo da deflação, conforme mencionado por ANDIMA (2008) e Fróes Júnior et al. (2019):

$$
\mathrm{PR}=\left(\frac{\mathrm{IGPI_{t }}}{1 \mathrm{GPDI}}\right)_{0}^{\star} \mathrm{PN}
$$

Em que:

PR - preço real em fev. 2019, ajustado com base na deflação do IGP-DI;

$P N$ - valor de preço nominal registrado no mês a ser deflacionado;

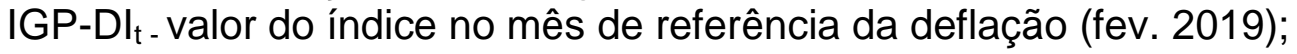

IGP-DI 0 - valor do índice no mês a ser deflacionado.

Contou-se, ainda, com informações de campo levantadas junto a atores locais. Os dados de produção da pitaya entre as regiões brasileiras, os estados, os municípios do Estado do Pará e ranking de frutas produzidas na unidade federativa foram analisados por meio de estatística descritiva. Tanto a produção, quanto o preço foram analisados no programa Microsoft Office Excel 2016 e são apresentados em forma de gráficos e tabelas neste estudo.

\section{A pitaya ao redor do mundo}

\section{RESULTADOS}

O monitoramento de informações de produção da pitaya no mundo, ainda se mostra um tanto limitado e não padronizado. Percebe-se que as estatísticas levantadas para a cultura, no geral, se restringem a estudos isolados.

Dessa forma, com o propósito de ilustrar as estatísticas de produção disponíveis sobre a pitaya no mundo, foi tomado como base o estudo de MercadoSilva (2018) como representado na Figura 1. 


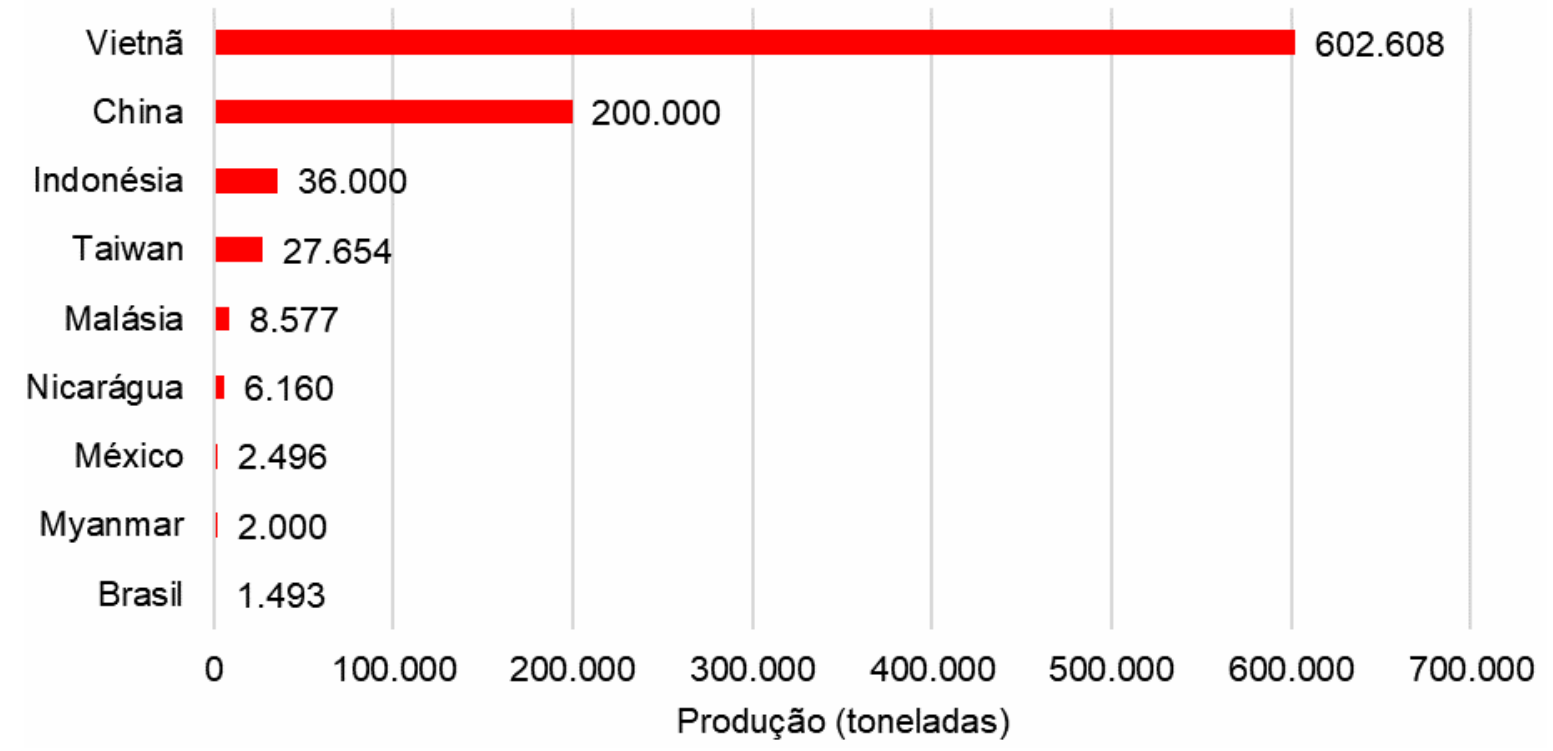

FIGURA 1. Principais países produtores de pitaya, em 2014 (valores em toneladas). Fonte: Mercado-Silva, 2018; IBGE, 2019.

Nota: (1) as estatísticas para produção da pitaya em alguns países ainda são pouco exploradas. Dessa forma, determinados países produtores do fruto não apresentam dados disponíveis; (2) a informação sobre a produção do Brasil é referente ao ano de 2017.

Como observado na Figura 1, em 2014, o Vietnã foi o principal produtor de pitaya do mundo, produzindo 602.608 toneladas do fruto, o que equivale, praticamente, a três vezes a produção da China (200 mil toneladas a mais). $\mathrm{O}$ restante dos países do ranking, produziram menos de 50 mil toneladas, como visto nos casos da Indonésia, Taiwan, Malásia, Nicarágua, México, Myanmar e Brasil.

Hoat et al. (2018) reforça que o Vietnã é o principal produtor, apresentando para o ano de 2015 uma produção de cerca de 686.195,40 toneladas. Esse valor é 83 mil toneladas a mais do que o apresentado no estudo de Mercado-Silva (2018) que tomou como base o ano de 2014.

$\mathrm{Na}$ América Latina, além do México, a produção do fruto se encontra distribuída nos países da Costa Rica, Venezuela, Panamá, Uruguai, Brasil e Colômbia (SATO et al., 2014).

De forma geral, a pitaya se mostra como uma cultura exótica e que apresenta uma perspectiva de crescimento de produção e aceitabilidade do mercado consumidor. Perween et al. (2018) afirmam que o crescimento comercial do produto tem ocorrido principalmente em países como Israel, Vietnã, Taiwan, Nicarágua, Austrália e nos Estados Unidos.

Segundo Nunes et al. (2014) atualmente essa planta vem ocupando um crescente nicho no mercado de frutas exóticas na Europa e Estados Unidos, atraindo a atenção de comerciantes e consumidores, devido as suas características sensoriais e nutracêuticas, além da aparência exótica (ESQUIVEL; AYARAQUESADA, 2012).

A plataforma TRIDGE (2019) destacava que os principais fornecedores de pitaya são os países asiáticos como: Vietnã $(38,20 \%)$, Tailândia $(20,22 \%)$ e a China $(10,11 \%)$. Segundo Mercado-Silva (2018) os maiores importadores da fruta no mundo são: Estados Unidos (17\%), Alemanha (14\%), França (12\%), Holanda (11\%), Rússia (10\%), Reino Unido (9\%), Canadá ( $8 \%)$. Sendo que a União Europeia é a principal região importadora com cerca de $57 \%$ da produção mundial. A TRIDGE 
(2019) também indicava que em meados de abril de 2019 o preço médio global era de US\$ 3,64 por kg.

Perween et al. (2018), chamam a atenção de que em razão da rusticidade da cultura, a planta é capaz de sobreviver a condições climáticas adversas de regiões áridas e semiáridas, sendo que o gênero Hylocereus $s p$. está atualmente distribuído ao redor de todo mundo, nas regiões tropicais e subtropicais.

Mizrahi (2014), por sua vez, destaca que apesar do Vietnã liderar a produção e exportação do fruto no mundo, o produto proveniente do país não é de boa qualidade genética, tendo clones que produzem um fruto com sabor um tanto sem graça e que tem sido cultivado em várias regiões ao redor do globo, sendo um problema relevante para a aceitação do produto em mercados convencionais.

\section{A pitaya no Brasil}

No cenário nacional, com base nos dados do Censo Agropecuário 2017 o Brasil, em 2017, produziu cerca de 1.493,19 toneladas de pitaya, em 3.086 estabelecimentos agropecuários (IBGE, 2019).

De acordo com Nunes et al. (2014) são poucos os estabelecimentos agrícolas produtores de pitaya no Brasil. Baseado em dados do IBGE (2019), dos 13.664.748 estabelecimentos agropecuários de lavoura permanente e temporária do Brasil, somente $0,02 \%$ são produtores da fruta. Tal fator acarreta na maior presença do produto importado no mercado brasileiro, em razão da baixa oferta interna. Dessa forma, por suas características comerciais, a cultura tem um comércio restrito e o preço elevado, tornando-a de consumo elitizado.

A produção da cultura está atualmente concentrada na região Sudeste, com cerca de 812,64 toneladas produzidas em 2017, contribuindo com $54,42 \%$ da produção nacional. A região Sul com 502,08 toneladas, responde por $33,62 \%$ da produção e a Norte, com 157,01, por $10,52 \%$ da produção nacional, são as três regiões mais representativas nesse cultivo, conforme dados apresentados na Tabela 1.

TABELA 1. Produção de pitaya entre as regiões brasileiras, 2017.

\begin{tabular}{l|r|r}
\hline Regiões & Produção (Ton.) & Participação (\%) \\
\hline Sudeste & 812,64 & 54,42 \\
Sul & 502,08 & 33,62 \\
Norte & 157,01 & 10,52 \\
Centro Oeste & 12,35 & 0,83 \\
Nordeste & 9,12 & 0,61 \\
Brasil & $\mathbf{1 . 4 9 3 , 1 9}$ & $\mathbf{1 0 0 , 0 0}$ \\
\hline
\end{tabular}

Fonte: IBGE, 2019.

O Sudeste do Brasil tornou-se a principal produtora de pitaya do País em razão de sua boa aclimatação da cultura na região (NUNES et al., 2014). Outro aspecto que aparenta ter contribuído para o aumento da produção na região é a mudança de comportamento do consumidor no Estado de São Paulo, que segundo o SEBRAE (2017) começou a se interessar mais pelo consumo de frutas exóticas.

Em 2017, o Estado de São Paulo foi o maior produtor nacional da cultura com 516,20 toneladas no ano, seguido por Santa Catarina (328,49 toneladas), Minas Gerais (185,91 toneladas) e o Estado do Pará (156,39 toneladas; 99,60\% da Região Norte). O Rio de Janeiro ocupa a $5^{\mathbf{a}}$ posição, com uma produção de 55 toneladas a menos que o Pará, como observado na Figura 2 (IBGE, 2019). 


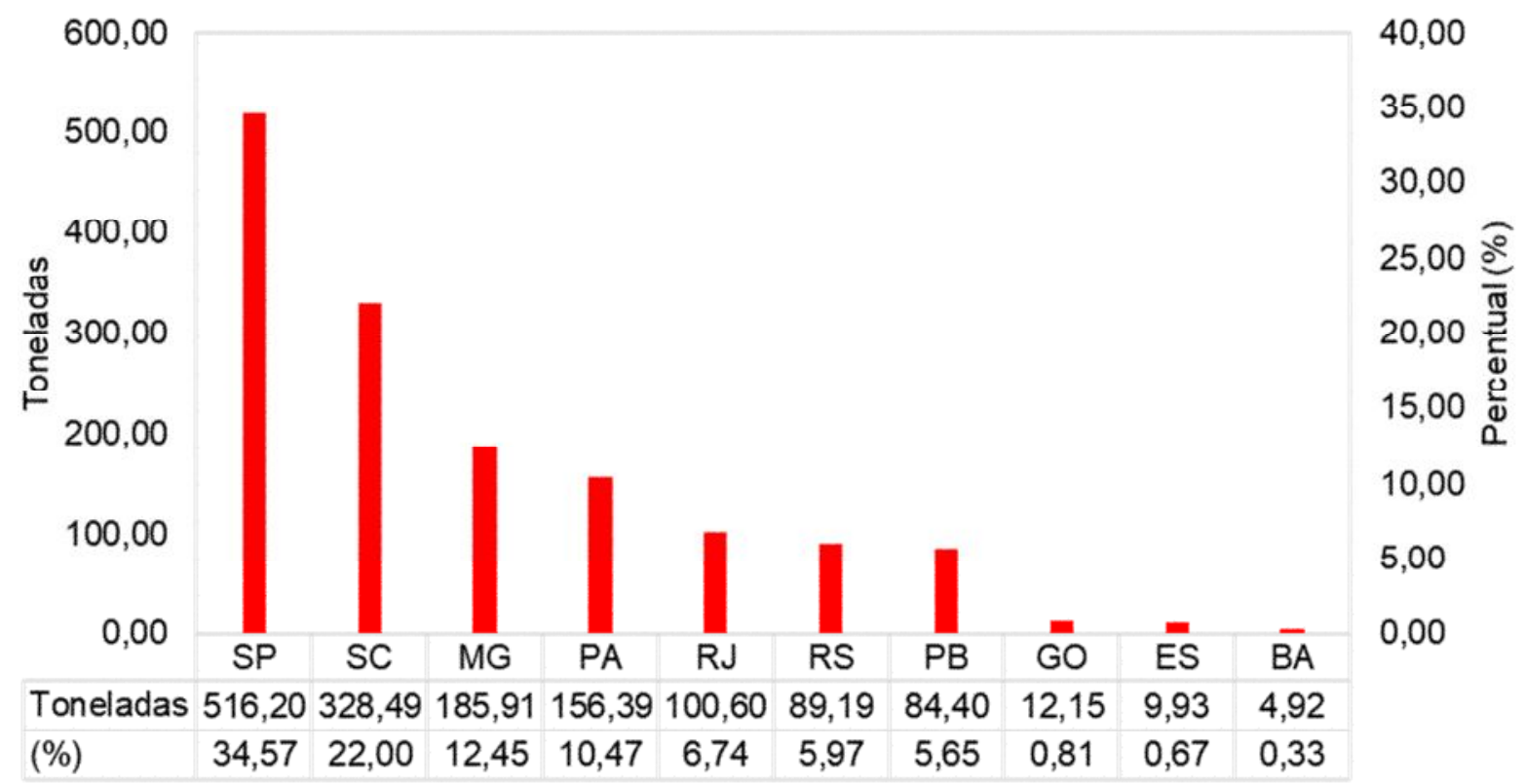

FIGURA 2. Produção em toneladas e percentual dos 10 principais estados brasileiros produtores de pitaya no ano de 2017.

Fonte: IBGE, 2019.

No Brasil, segundo Nunes et al. (2014) a espécie Hylocereus undatus passou a ser cultivada na década de 1990, no Estado de São Paulo. Em 2000 outras espécies como a Hylocereus polyrhizus foram introduzidas, também sendo reportada por Junqueira et al. (2002) a espécie Selenicerus setaceus.

\section{A pitaya no cenário paraense}

A pitaya, assim como em muitas outras regiões do Brasil, é pouco conhecida pelo mercado consumidor paraense. No entanto, percebe-se que a cultura se adaptou muito bem as condições edafoclimáticas da Amazônia.

Os dados do Censo Agropecuário 2017 (IBGE, 2019) revelam que a produção de pitaya no Estado do Pará é equivalente a 156,385 toneladas, sendo que a produção está concentrada no Nordeste Paraense, principalmente no município de Tomé-Açu, Acará e Aurora do Pará como observado na Tabela 2.

TABELA 2. Principais municípios paraenses produtores de pitaya, 2017.

\begin{tabular}{l|r|r}
\hline Município & Produção (Ton.) & Participação (\%) \\
\hline Tomé-Açu & 92,70 & 59,28 \\
Acará & 26,45 & 16,91 \\
Aurora do Pará & 24,00 & 15,35 \\
Vitória do Xingu & 0,30 & 0,19 \\
Concórdia do Pará & 0,10 & 0,06 \\
Outros municípios & 12,84 & $\mathbf{8 , 2 1}$ \\
Pará & $\mathbf{1 5 6 , 3 9}$ & $\mathbf{1 0 0 , 0 0}$ \\
\hline
\end{tabular}

Fonte: IBGE, 2019.

Os municípios de Vitória do Xingu e Concórdia do Pará produziram, respectivamente, $300 \mathrm{~kg}$ e $100 \mathrm{~kg}$ do fruto como registrado pelo IBGE (2019), sendo que o restante dos municípios do Estado mostra valores inexpressivos na estatística 
do Censo Agropecuário de 2017, mas contabilizam juntos cerca 12,84 toneladas da produção estadual. Foram registrados 77 estabelecimentos com mais de 50 pés cultivados com pitaya no Pará.

Sato et al. (2014) acrescenta que a pitaya também é produzida nos municípios de Castanhal, Santo Antônio do Tauá e Santa Izabel do Pará, contudo a produção não é documentada pela estatística do IBGE, talvez pela expressividade incipiente. Os autores também afirmam que a principal espécie produzida no estado é a pitaya vermelha de polpa vermelha (Hylocereus costaricensis).

Em Tomé-Açu é observado que os pitayicultores recebem auxílio técnico e de pesquisa proveniente do "Projeto Pitaya" realizado pela Universidade Federal Rural da Amazônia (UFRA), campus de Tomé-Açu, que objetiva aprofundar os conhecimentos de adaptação da planta as condições edafoclimáticas, de nutrição vegetal e produção de mudas da cultura (UFRA, 2016). O projeto de pesquisa iniciou em 2016 e trabalha em parceria com a Secretaria Municipal de Agricultura do Município de Tomé-Açu (SEMAGRI), a Cooperativa Agrícola Mista de Tomé-Açu (CAMTA), entre outros colaboradores.

\section{Produção agrícola no Estado do Pará}

No Estado do Pará, como o cultivo de pitaya ainda é bastante recente, observa-se que os pequenos produtores são os principais agentes dessa cadeia, iniciando a entrada de médios empreendimentos com expertise na produção intensiva do fruto.

Ao comparar o quantitativo produzido de outras frutas no Estado do Pará com a produção da pitaya, percebe-se que a participação da fruta ainda é muito incipiente frente as demais, representando somente $0,02 \%$ do percentual total das fruteiras documentadas na estatística do IBGE, como observado na Tabela 3.

TABELA 3. Ranking das principais frutas produzidas no estado do Pará, inclusive da pitaya em produção e participação relativa, 2017.

\begin{tabular}{l|r|r}
\hline Frutos & Produção (Toneladas) & $\mathbf{( \% )}$ \\
\hline Açaí & $272.649,00$ & 37,56 \\
Coco-da-baía & $173.788,00$ & 23,94 \\
Laranja & $62.193,00$ & 8,57 \\
Cacau (amêndoa) & $56.495,00$ & 7,78 \\
Banana & $44.826,00$ & 6,17 \\
Melancia & $43.172,00$ & 5,95 \\
Limão & $28.366,00$ & 3,91 \\
Tangerina, bergamota, mexerica & $12.742,00$ & 1,76 \\
Mamão & $7.092,00$ & 0,98 \\
Maracujá & $6.237,00$ & 0,86 \\
Cupuaçu & $4.687,00$ & 0,65 \\
Castanha-do-Pará & $4.186,00$ & 0,58 \\
Acerola & $4.073,00$ & 0,56 \\
Pupunha & $1.554,00$ & 0,21 \\
Goiaba & $1.531,00$ & 0,21 \\
Caju & 863,00 & 0,12 \\
Graviola & 405,00 & 0,06 \\
Jaca & 288,00 & 0,04
\end{tabular}




\begin{tabular}{l|r|r} 
Abacate & 199,00 & 0,03 \\
Abacaxi & 143,71 & 0,02 \\
Manga & 157,00 & 0,02 \\
Pitaya & $\mathbf{1 5 6 , 3 9}$ & $\mathbf{0 , 0 2}$ \\
Melão & 124,00 & 0,02 \\
Lima & 47,00 & 0,01 \\
Guaraná & 14,00 & 0,00 \\
Jabuticaba & 5,00 & 0,00 \\
\hline
\end{tabular}

Fonte: IBGE, 2019.

A fruticultura no Estado do Pará é bem diversificada e muito mais extensa do que a explicitada na Tabela 3, que contempla as frutas com informações estatísticas oficiais. As frutas regionais consideradas invisíveis à luz das estatísticas, são mais de 200, a exemplo do bacuri, uxi, taperebá e muruci, sendo que a grande maioria ainda não é domesticada. O Açaí, por exemplo, que no passado recente era restrito ao consumo local e regional, tem se expandido fortemente no mercado nacional e para alguns nichos no mercado global. Sobre a fruticultura paraense ver, por exemplos, os recentes trabalhos de Costa et al. (2017), Fróes Júnior et al. (2019), Silva Júnior et al. (2019).

Apesar da baixa quantidade produzida de pitaya, o fruto consegue atender uma demanda de mercado singela, em razão de ainda ser pouco consumida pela população paraense por conta de seu preço ser considerado elevado. $O$ manejo e planejamento da cultura ainda não são normatizados, visto que essa planta é exótica e de introdução recente e, portanto, carece de muitos estudos para a padronização do sistema de produção. Apesar das limitações sobre o seu processo de produção, um único hectare pode acomodar em torno de 800 plantas da fruta (PERWEEN et al., 2018).

O fruto possibilita alta densidade de renda por área. A produtividade pode alcançar cerca de 25 a 30 toneladas por hectare sob condições climáticas ideais, após os três anos de implantação (PITAYA DO BRASIL, 2019). Segundo Mizrahi (2014) esse rendimento pode ser ainda maior com uma adubação mineral adequada, podendo chegar até 45 toneladas por hectare ano.

Moreira et al. (2012) afirmam que a pitaya é uma cultura perene com expectativa de produção de mais de 15 anos. Para Perween et al. (2018) o ciclo de vida da planta pode chegar a 20 anos. Dessa forma são necessários o planejamento da cultura em campo e a busca por informações sobre a adaptação da planta na região, objetivando o melhor desenvolvimento e produtividade do plantio, também devido ao alto custo de implantação (REZENDE et al., 2017).

Segundo Pitaya do Brasil (2019) o plantio da cultura pode ser realizado durante todo o ano, entretanto é necessário evitar os meses mais quentes e frios (geadas). Apesar dessa afirmação, observa-se a necessidade de pesquisas voltadas aos tratos culturais e comportamento quanto ao clima da cultura nos municípios paraenses.

Sato et al. (2014) afirmam que no Nordeste Paraense a pitaya costuma produzir o ano todo, mas a cultura apresenta dois períodos principais de safra: um com floração em junho e colheita em julho e agosto e outro com floração em dezembro e colheita de janeiro e fevereiro.

Perween et al. (2018) afirmam que as espécies de Hylocereus são semi epífitas e em consequência disso, desenvolvem-se melhor em condições de meia 
sombra. Contudo, as espécies $H$. undatus, $H$. costaricensis e $H$. purpusii, conseguem se desenvolver bem a pleno sol. Os autores, no entanto, destacam que condições de sol pleno, com temperaturas elevadas e regime hídrico insuficiente, podem queimar o caule e abortar o botão floral.

A pitaya possui capacidade de adaptação ao clima tropical, subtropical ou árido, dessa forma, a umidade não é um fator limitante ao seu desenvolvimento. No entanto, condições de elevada umidade favorecem infecções por fungos e bactérias no caule e frutos, o que pode prejudicar o cultivo (REZENDE et al., 2017).

O Estado do Pará é caracterizado por ser uma região de clima quente e úmido, fator que pode ser extremamente prejudicial para implantação de mudas, visto que a condição climática favorece 0 ataque de fitopatógenos como, por exemplo, os do reino fungi.

O fruto se desenvolve bem em altitudes de até 1.000 metros acima do nível do mar. A temperatura média adequada é de 18 a 26 graus centígrados e o regime hídrico de 1.200 a $1.500 \mathrm{~mm}$ ao ano, podendo também se desenvolver em clima mais seco (PITAYAS DO BRASIL, 2019).

Quanto às condições do solo, para a cultura é ideal que esse apresente o pH entre 5,5 e 6,5, rico em material orgânico, bem drenados e de textura bem solta (REZENDE et al., 2017). De acordo com Cordeiro et al. (2015) para a pitaya não se costuma utilizar adubação química, pois ainda não há uma recomendação para a cultura.

Para Mizrahi (2014) dados sobre as necessidades de fertilização mineral da cultura ainda precisam ser mais explorados, assim como a demanda exata para vários nutrientes minerais é desconhecida.

O sistema de plantio recomendado na maioria dos estudos sobre pitaya é o de estaquia e tutoramento (MOREIRA et al., 2017; JUNQUEIRA et al., 2002). Nesse sistema as plantas têm seu sentido de crescimento guiado na vertical, no sentido das estacas, por meio de pequenas cordas ou arames. Na parte superior das estacas fixam-se arames para que as plantas cresçam verticalmente até eles, e se espalhe horizontalmente, em decorrência do seu comportamento de liana (REZENDE et al., 2017).

De acordo com Moreira et al. (2012) a muda deve ser plantada a cinco centímetros acima do nível do solo para que, após a irrigação e compactação, a muda fique ao nível do mesmo, visando evitar o soterramento da planta que pode causar apodrecimento. Deve-se ter cuidado para apertar bem a muda na cova no momento do plantio, evitando deixar espaços vazios. Por ser uma planta trepadeira deve-se fazer o tutoramento da muda com um mourão de aproximadamente $1,80 \mathrm{~m}$ de altura, na extremidade desse mourão recomenda-se colocar uma trave ou qualquer outro tipo de suporte para sustentação das brotações produtivas. Além disso, é indicado fazer o amarrio da muda com barbante para facilitar o crescimento acompanhando o sentido do mourão.

No município de Tomé-Açu (PA) a bucha de dendê é utilizada como cobertura vegetal para o solo. Como a região e localidades vizinhas possuem grandes plantios de dendezeiros, os produtores de pitaya utilizam esse material para manter a umidade do solo e fornecer nutrição orgânica para as plantas.

Nos sistemas de produção de pitaya adotados no Brasil, alguns produtores implantam duas plantas por estacas, posicionadas nas faces opostas de cada tutor. Não se constatou a realização de estudos comprovando a eficiência dessa prática de manejo, visto que ela pode provocar a competição por água e nutrientes pelas plantas. 


\section{Produção de mudas}

No cultivo de mudas de pitaya, a recomendação técnica é a utilização do método de propagação assexuada (vegetativa), objetivando propiciar a precocidade e uniformidade genotípica dos pomares, ideal para a multiplicação comercial de espécies frutíferas perenes, sendo utilizado principalmente após a seleção das cultivares de maior interesse (MOREIRA et al., 2017).

A estaquia é um dos processos de propagação vegetativa que proporciona a fixação de genótipos selecionados, uniformidade de populações, antecipação do florescimento, redução do estádio juvenil, além de apresentar maior facilidade de propagação e proporcionar maior controle das fases de desenvolvimento (MOREIRA et al., 2017).

A formação do sistema radicular ocorre no período de 30 a 60 dias após o plantio, seguido pelo surgimento de novas brotações. É recomendado que a condução das mudas seja feita sob sombrite por período de 10 a 15 meses para manter o crescimento dos cladódios, até atingir 2 a 3 brotos e então serem levadas a campo. A adubação nitrogenada de dois em dois meses, a partir do início do surgimento de novas brotações, favorece o crescimento vegetativo, sendo indicado diluir 10 gramas de ureia em 10 litros de água e, posteriormente, distribuir $100 \mathrm{ml}$ da solução por muda (MOREIRA et al., 2017).

É indicado que antes de levar a muda ao campo ela passe por um período de aclimatação, deixando-a por uma ou duas semanas fora do sombrite, visando receber maior insolação (MOREIRA et al., 2017). De acordo com Cordeiro et al. (2015) ainda não há registro de nenhuma variedade de pitaya que seja recomendada por órgãos de pesquisa agropecuária do País. As mudas comercializadas não são de material selecionado e nota-se a variação na produção, tamanho, formato e características físico-químicas dos frutos. Isso, de certa forma, acaba por dificultar o acesso ao crédito e a expansão comercial da cultura junto aos pequenos agricultores como destacam, por exemplo, estudos de Rebello e Homma (2017) e Fróes Júnior et al. (2019) sobre a economia rural na Amazônia.

Acredita-se que essa desuniformidade vigente nas mudas do fruto, pode causar um efeito negativo direto no comportamento do mercado, pois como não ocorre o processo de melhoramento genético da planta, o sabor do produto pode ser influenciado, levando o consumidor que desconhece o produto a perder interesse em consumir a pitaya novamente, devido a experiências sensórias desagradáveis com o consumo de frutos sem as características gustativas dos bons frutos.

\section{Colheita e pós colheita}

A colheita do fruto é realizada, de forma geral, quando o fruto atinge o estágio completo de maturação. Nunes et al. (2014) afirmam que apesar do fruto ser colhido nesse estágio, ainda não existe um consenso na literatura sobre o comportamento climatérico desses frutos. A planta produz frutos a partir do segundo ano de plantio, atingindo a sua máxima produção após cinco anos (PERWEEN et al., 2018).

A escassez da oferta e, consecutivamente, os preços elevados contribuem para o baixo consumo da fruta. Dessa forma, uma significativa parcela da população não consome o produto fazendo com que a demanda tenda a ser baixa, quando comparada com outras frutas. $\mathrm{O}$ empreendedor que visa ingressar nesse ramo deve atentar para a apresentação do fruto, tanto nos aspectos relacionados ao sabor quanto na aparência.

Mizrahi (2014) destaca que o fruto pode sofrer alterações no sabor em razão de diversos fatores. Segundo o autor, uma das condições para que isso não ocorra 
no mercado é assegurar a procedência do material genético, evitando o clone do Vietnã que é descrito como frutos com o sabor "bastante sem graça".

Ainda de acordo com o Mizrahi (2014), devido a procedência da maior parte dos clones do mundo serem do Vietnã, criou-se um obstáculo para a conversão da cultura de exótica para convencional, visto que consumidores que degustaram essas frutas, relutam experimentar as novas variedades existentes hoje, tendo a necessidade de resolução desse obstáculo de marketing.

Visto ser um produto novo no mercado, o desconhecimento do sabor pela grande maioria dos consumidores pode levar muitas vezes as pessoas a terem percepções iniciais precipitadas em relação ao fruto.

Junqueira et al. (2002) afirmam que o fruto no geral apresenta valores de sólidos solúveis de graus Brix entre 13 a 15․ No estudo de Cordeiro et al. (2015) sobre a composição físico-química e nutricional da pitaya rosa de polpa vermelha (Hylocereus polyrhizus), mostrou que os frutos estudados apresentavam valores de sólidos solúveis, $\mathrm{pH}$ e acidez titulável de: 13,14 Brix; 5,60; 0,29 mg de ácido málico 100-1 mL, respectivamente.

Em outro estudo, Enciso et al. (2011) mostraram que em frutos maduros de pitaya que a acidez titulável reduzia cerca de $80 \%$ após a colheita. Sendo que no primeiro dia essa quantidade era de $0,63 \mathrm{mg}$ de ácido málico e depois de 12 dias passou para $0,10 \mathrm{mg}$. Na mesma pesquisa os autores encontraram valores de sólidos solúveis entre 11,6 e 13,6ํㅡㄹ Brix para frutos completamente maduros.

$\mathrm{Na}$ pesquisa de Sato et al. (2014) realizado em plantas cultivadas em três municípios do Estado do Pará (Castanhal, Tomé-Açu, Santa Izabel do Pará), observou-se que os valores de $\mathrm{pH}$, sólidos solúveis e acidez titulável em porcentagem de ácido cítrico (AC) dos frutos foram de: 4,75, 10,13ํㅜㅅㅜ e 0,14 mg de AC em Castanhal; 4,25, 10,90ํㅡㄹ e 0,18 mg de AC em Tomé-Açu; e, 4,02, $12,17^{\circ}$ Brix e $0,20 \mathrm{mg}$ de AC nas pitayas provenientes de Santa Izabel do Pará. O ideal é que o fruto tenha sabor longe do neutro e com sensação ácida mais acentuada, semelhante à do kiwi (Actinidia deliciosa).

A conservação do produto também se mostra como um fator importante na etapa de pós colheita e comercialização. Mizrahi (2014) afirma que após a colheita, os frutos começam a ter um declínio acentuado na acidez. Além disso, a aparência dos frutos começa a se debilitar, principalmente devido ao encolhimento das escamas das frutas.

No município de Tomé-Açu (PA), no início de abril de 2019, o preço pago ao produtor pelo quilo do fruto in natura, pela CAMTA, era da ordem de $R \$ 2,40 / \mathrm{Kg}$, enquanto que o quilo da polpa era comercializado por $R \$ 7,50$. Essa mesma quantidade de polpa $(\mathrm{kg})$, quando comercializada em pacotes de $100 \mathrm{~g}$ atingia 0 preço de $R \$ 9,00$. Os custos com a embalagem e mão de obra explicam essa diferença de preço. A CAMTA tem efetuando a mistura da polpa de pitaya com a de açaí para atender pedido específico de um grande importador internacional. 
A Figura 3, mostra os preços da pitaya praticados na CEASA-PA entre março de 2017 a janeiro de 2019 no município de Belém, capital do Estado do Pará.

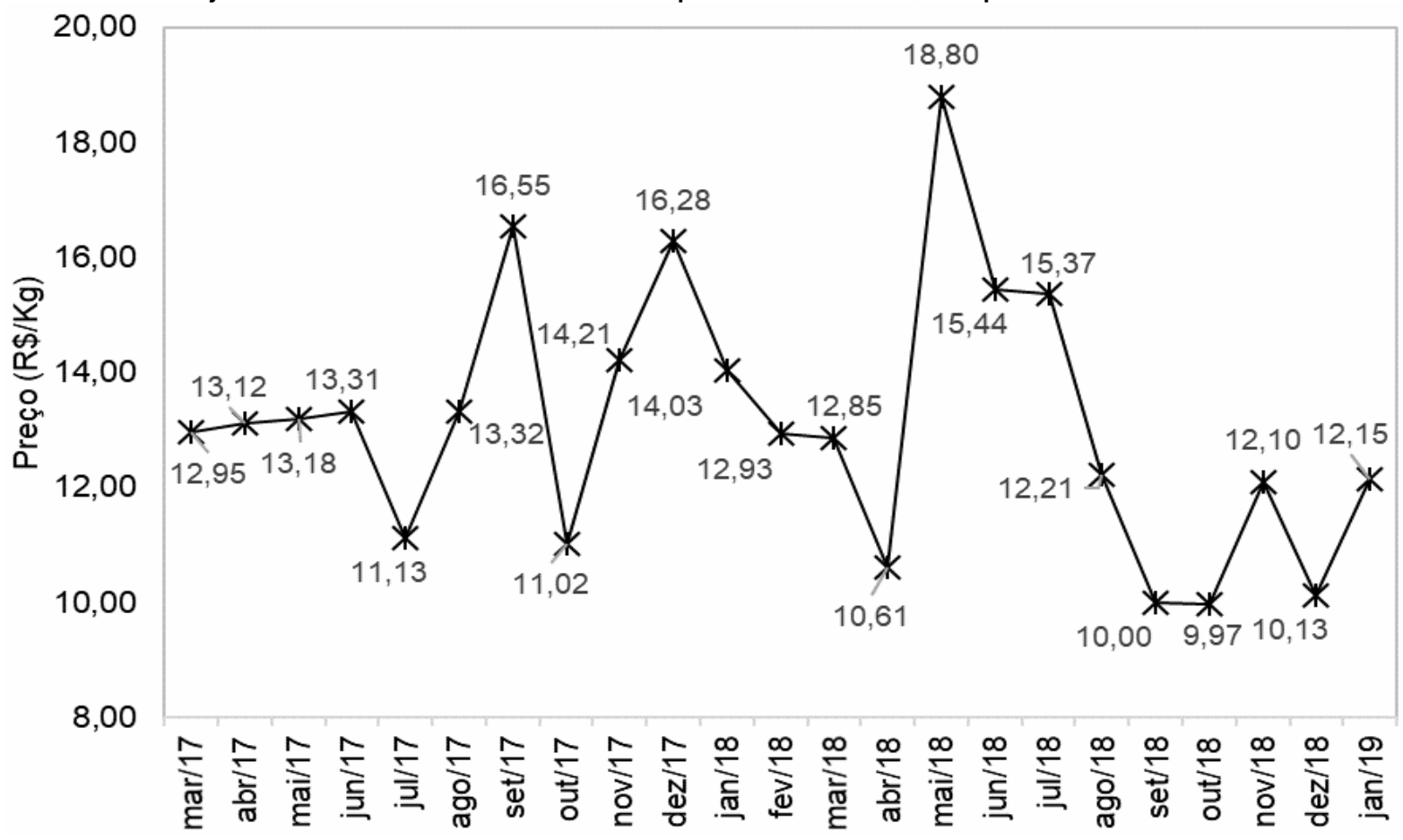

FIGURA 3. Preço $(R \$ / \mathrm{kg})$ da pitaya na CEASA-PA, no período entre março de 2017 a janeiro de 2019.

Fonte: CEASA, 2019.

Nota: dados de preços deflacionados para fevereiro de 2019.

Observando a conjuntura de preços do fruto na CEASA-PA, percebe-se que a média dos preços durante todo período considerando é de $\mathrm{R} \$ 13,12$ por $\mathrm{kg}$ de fruto. O menor preço foi de $R \$ 9,97 / \mathrm{kg}$ em outubro de 2018 e o maior foi de $R \$ 18,80 / \mathrm{kg}$ em maio de 2018. Apesar da oscilação de preços, a pitaya ainda é considerada bastante cara para a maioria da população paraense.

Além disso, os frutos são comercializados em feiras livres, supermercados e fruteiras no Estado, principalmente em Belém, sendo que também é possível observar essa comercialização em pequenas quantidades em fruteiras nas rodovias, especialmente próximo aos municípios produtores. Uma das dificuldades para a sua comercialização é a relativa perecibilidade, exigindo muito cuidado no transporte e conservação.

Quanto ao mercado, observa-se uma importante possibilidade para realização de estudos socioeconômicos que levantem informações sobre a propensão a consumir pelo fruto, dada algumas condições a serem testadas junto ao consumidor belenense e de outros centros representativos no Estado do Pará. Na mesma linha, pelo lado da oferta (produção), seria importante a condução de estudos sobre o custo de produção e viabilidade econômica do sistema de cultivo da pitaya nas condições locais. 


\section{CONCLUSÕES}

A produção paraense da pitaya ainda se mostra bastante incipiente quando comparada com outras fruteiras cultivadas na região. Foi possível verificar que para a maior parte da população consumidora no mercado local, o preço do fruto é bastante elevado.

Por se tratar de um produto relativamente novo, a introdução de cultivares que produzam frutos com um sabor agradável e com níveis de acidez adequado é essencial para influenciar positivamente o mercado consumidor que está sendo apresentado a pitaya.

Ademais, os levantamentos de informações sobre produção, comercialização e aspectos socioeconômicos que envolvem a cultura são de extrema importância para compreensão desse novo mercado e para elaboração de estratégias que estimulem a produção do fruto na economia paraense.

\section{REFERÊNCIAS}

ANDIMA - Associação Nacional das Instituições do Mercado Financeiro. Metodologia de cálculo dos valores nominais atualizados. São Paulo: ANDIMA, 2008. 6 p.

CEASA-PA - Centrais de Abastecimento do Pará . Cotação de Preços. 2019. Disponível em: http://www.ceasa.pa.gov.br/cotacao. Acesso em: 21 mar. 2019.

CORDEIRO, M. H. M.; SILVA, J. M.; MIZOBUTSI, G. P.; MIZOBUTSI, E. H.; MOTA, W. F. Caracterização física, química e nutricional da pitaia-rosa de polpa vermelha. Revista Brasileira de Fruticultura, Jaboticabal, v.37, n.1, p. 20-26, mar. 2015. http:// dx.doi.org/10.1590/0100-2945-046/14.

COSTA, M. R. T. R.; HOMMA, A. K. O.; REBELLO, F. K.; SOUZA FILHO, A. P. S.; FERNANDES, G. L. C.; BALEIXE, W. Atividade Agropecuária no Estado do Pará. Belém: Embrapa Amazônia Oriental, 2017. Disponível em: https://www.embrapa. br/busca-de-publicacoes/-/publicacao/1073940/atividade-agropecuaria-no-estado-dopara. Acesso em: 17 mar. 2019. 174 p.

ENCISO, T. O.; ZAZUETA, M. E. I.; M. RANGEL, M. D. M.; TORRES, J. B. V.; ROMERO, M. V.; VERDUGO, S. H. Calidad post cosecha de frutos de pitahaya (Hylocereus undatus haw.) cosechados entres estados de madurez. Revista Fitotecnia Mexicana. Chapingo. v. 34, n. 1, p. 63-72, 2011. Disponível em: https://www.revistafitotecniamexicana.org/documentos/341/8a.pdf. Acesso em: 06. mai. 2019.

ESQUIVEL, P. Los frutos de las Cactáceas y su potencial como matéria prima. Agronomía Mesoamericana. v. 15, n.02, p. 215- 219.2004. DOI 10.15517/AM.V15I2.11916

ESQUIVEL, P.; AYARA-QUESADA, Y. Características del fruto de la pitahaya (Hylocereus sp.) y su potencial de uso en la industria alimentaria. Revista Venezolana de Ciencia y Tecnología de Alimentos, v.3, n.1, p.113-129. 2012. Depósito Legal: ppi201002CA3536. Disponível em: https:/sites.google.com/site/1rvcta/v3-n12012/r7. Acesso em: 06. mai. 2019. 
FRÓES JÚNIOR, P. S. M.; AVIZ, W. L.; REBELLO, F. K.; SANTOS, M. A. S. Sources of Growth and Spatial Concentration of Coconut Crop in the State of Pará, Brazilian Amazon. Journal of Agricultural Science; v. 11, n. 2, 2019. Disponível em: http:// dx.doi.org/doi:10.5539/jas.v11n2p159.

GREENME. Pitaya - Propriedades curativas e várias formas de consumir. 2017. Disponível em: https://www.greenme.com.br/usos-beneficios/4107-pitaiapropriedades -curativas-formas-consumir. Acesso em: 28 abr. 2019.

HOAT, T. X., QUAN, M. V., HIEN, N. T. T., NGOC, N. T. B., THANH, H. M., LIEM, N. V. Dragon Fruit production in Vietnam: Achievements and Challenges. FFTC Agricultural Policy Platform. 8 p. 2018. Disponível em: http://ap.fftc.agnet.org/files/ap_policy/873/873_1.pdf. Acesso em: 02. mai. 2019.

HOMMA, A. K. O. A Terceira Natureza da Amazônia. Revista Paranaense de Desenvolvimento, v. 38, p. 27-42, 2017.

IBGE - Instituto Brasileiro de Geografia e Estatistica . Resultados do Censo Agropecuário 2017. Disponível em: https://censos.ibge.gov.br/agro/2017/. Acesso em: 01 mar. 2019.

IPEA - Instituto de Pesquisa Econômica Aplicada. IPEAData - Macroeconômico: Preço IGP-DI. 2019. Disponível em: http://ipeadata.gov.br. Acesso em: 21 mar. 2019.

JUNQUEIRA, K. P.; JUNQUEIRA, N. T. V.; RAMOS, J. D.; PEREIRA, A.V.; Informações preliminares sobre uma pitaya (Selenicereus setaceus Rizz) nativa do Cerrado. Planaltina: EMBRAPA, 18p. (Documentos, 62). 2002. Disponível em: https://www.infoteca.cnptia.embrapa.br/bitstream/doc/566991/1/doc62.pdf.

MELQUÍADES JÚNIOR. Pitaya: Beleza poderoza. Diário do Nordeste, fev. 2018. Disponível em: https://diariodonordeste.verdesmares.com.br/editorias/verso/pitayabeleza-poderosa-1.1898296. Acesso em: 29 abr. 2019.

MERCADO-SILVA, E. M. Pitaya - Hylocereus undatus (Haw). Exotic Fruits Reference Guide. p. 339-349. 2018. doi:10.1016/b978-0-12-803138-4.00045-9

MIZRAHI, Y.; NERD, A.; NOBEL, P. S. Cacti as Crops. Horticultural Reviews, p. 291-319. 1997. https://doi.org/10.1002/9780470650608.ch6.

MIZRAHI, Y. Vine-cacti Pitayas: the new crops of the world. Revista Brasileira de Fruticultura, Jaboticabal, v. 36, n. 1, p. 124-138, mar. 2014. http://dx.doi.org/10.1590/01002945-452/13.

MOREIRA, R. A.; RAMOS, J. D.; SILVA, F. O. R.; MARQUES, V. B. Cultivo da Pitaya: Implantação. Boletim Técnico. n. 92, p. 1-16. Lavras/MG. 2012.

MOREIRA, R. A.; RAMOS, J. D.; SILVA, F. O. R.; MOREIRA, R. A. Produção de mudas de Pitaya. Boletim Técnico. n. 103, p. 1-11. Lavras/MG. 2017. 
NUNES, E. N.; SOUSA, A. S. B.; LUCENA, C. M.; SILVA, S. M.; LUCENA, R. F. P.; ALVES, C. A. B.; ALVES, R. E. Pitaia (Hylocereus $s p$.): Uma revisão para o Brasil. Revista Gaia Scientia. v.8, n.1, p. 90-98. 2014. ISSN 19811268. http://periodicos.ufpb.br/ojs2/index.php/gaia/index.

PERWEEN, T.; MANDAL, K.; HASAN, M.; Dragon fruit: An exotic super future fruit of India. Journal of Pharmacognosy and Phytochemistry. v.7, n.2, p. 1022-1026, 2018. E-ISSN: 2278-4136; P-ISSN: 2349-8234. Disponível em: http:/www.phytojournal.com/archives/2018/vol7issue2/PartO/7-1-435-453.pdf. Acesso em: 05. Abr. 2019.

PITAYA DO BRASIL. Sobre a Pitaya. Disponível em: https://www.pitayadobrasil.com.br/sobre-a-piatyal. Acesso em: 19. mar. 2018.

REBelLO, F. K.; HOMMA, A. K. O. História da colonização do Nordeste Paraense: reflexões para o futuro da Amazônia. Belém: EDUFRA, 2017.156 p.

REZENDE, I. F.; SOUSA, A. C. G; SUAREZ, N. F.; ROCHA, C. C.; RUFINI, J. C. M. Boletim de Extensão: $O$ cultivo da Pitaya. Boletim de Extensão. Universidade Federal de São João Del Rei, 18 p. 2017.

SATO, S. T.; RIBEIRO, S. C. A.; SATO, M. K.; SOUZA, J. N. S. Physical and physiochemical characterization of the pitayas red (Hylocereus costaricensis) produced in three cities of Pará. Journal of bioenergy and food science, [S.I.], v.1, n.2, nov. 2014. ISSN 2359-2710. Disponível em: http://periodicos.ifap.edu.br/index.php/JBFS/article/view/15. Acesso em: 27 mar. 2019. doi: http://dx.doi.org/10.18067/jbfs.v1i2.15.

SEBRAE - Serviço Brasileiro de Apoio às micro e pequenas Empresas. Análise de Tendência: Produza e comercialize frutas que estão conquistando o mercado. 2017. Disponível em: http://www.sebrae.com.br/sites /PortalSebrae/artigos/produza-e-comercializefrutas-que-estao-conquistando-o-mercado,ce73

75d380a9e410VgnVCM1000003b74010aRCRD. Acesso em: 19. mar. 2019.

SILVA JUNIOR, J. I. S.; REBELLO, F. K.; LIMA, H. V.; SANTOS, M. A. S.; SANTOS, P. C.; LOPES, M. L. B. Socio-economics of Açaí Production in Rural Communities in the Brazilian Amazon: A Case Study in the Municipality of Igarapé-Miri, State of Pará. Journal of Agricultural Science, v. 11, p. 215-224, 2019. doi:10.5539/jas.v11n5p215

TODAFRUTA. Pitaya. Disponível em: https://www.todafruta.com.br/pitaya. Acesso em: 31 mar. 2019.

TRIDGE - GLOBAL TRADE PLATAFORM. Intelligence: Dragon Fruit. 2019. Disponível em: https://www.tridge.com/intelligences/dragon-fruit. Acesso em: 29 abr. 2019.

UFRA - Universidade Federal Rural da Amazônia . Ufra Tomé-Açu realiza o primeiro experimento no campus. 2016. Disponível em: https://novo.ufra.edu.br /index.php ?option=com_content\&view=article\&id=636:ufra-tome-acu-realiza-primeiro-experimento-docampus\&catid=17\&ltemid=121. Acesso em: 30 mar. 2019. 